\title{
Venezuela: entre la continuidad y el cambio
}

Claudio H. Vargas

De nuevo para Silvia y por primera vez a Federico.

G n 1966, el economista venezolano Salvador de la Plaza señalaba en un breve ensayo que a pesar de su gran riqueza petrolera, explotada intensamente desde la segunda década del presente siglo, en Venezuela persistian signos inequívocos de subdesarrollo -entre los que destacó la obsolescencia de la estructura agraria y la dependencia económica del exterior-que comprometían seriamente la viabilidad de consolidar un régimen político democrático en el país. ${ }^{1}$

${ }^{1}$ Salvador de la Plaza, "Foreign exploitation of oil and national development", en Irving Louis
Este marcado escepticismo respecto a que en condiciones de subdesarrollo y dependencia -términos que en la tónica de los años sesenta se implicaban uno al otro-la democracia política venezolana tuviese oportunidad de sobrevivir, podría justificarse porque sólo habían pasado ocho años de que el general Marcos Pérez Jiménez había abandonado el país. Despues de todo, el fracaso reformista del "trienio" (1945-48) y la emergencia de la guerrilla, con el consecuente despliegue de represión contrain-

Horowitz, Josué de Castroy John Gerassi (comps.), Latin american radicalism. A documentaryreport on left and national movements, Vintage Books, Nueva York, 1969, p. 293. 


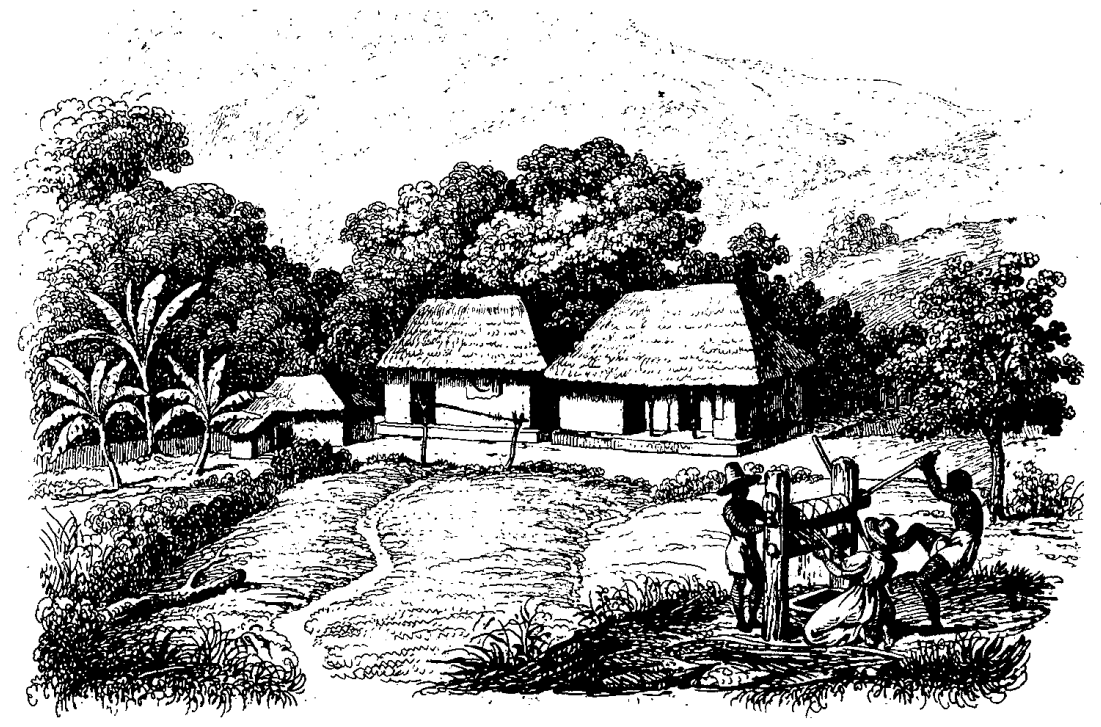

surgente a principios de la década de los sesenta, no permitian mayor certidumbre en relación con que los ciclos de autoritarismo o de dictaduras militares no. hubiesen podido reaparecer después de la llegada al poder de los civiles en 1958.

En 1990, con un balance insólito para la historia de América Latina, pues se ha consolidado un régimen político democrático -en el cual tres décadas de sucesiones de gobierno bajo un sistema electoral competitivo fueron fundamentales-y con la menos insólita realidad de un subdesarrollo realmente persistente, el escepticismo de De la Plaza aparece, si no del todo infundado, sí poco persuasivo. Esto no sólo para entender la experiencia venezolana sino también para apoyar la revisión crítica de los procesos políticos de otros países de la región que hoy enfrentan un arduo y dificil proceso de transición hacia la creación y consolidación de sistemas políticos posautoritarios.
Apenas es necesario insistir aquí que, como en el caso de Venezuela, las elecciones competitivas son un elemento crucial para la democratización de los régimenes políticos. Sólo agregaremos que es dificil pensar que sin la instauración de este tipo de sistemas electorales, la consolidación de regímenes democráticos en otros países de la región será aún más incierta y tensa.

Así, la peculiaridad del caso venezolano; sin que ello implique una idealización acrítica, nos invita a procurar análisis que permitan ir más allá de la trilogía subdesarrollo-dependencia-autoritarismo. Parece necesario explorar otras formas de entendimiento, no únicamente acerca de las relaciones entre sistemas económicos y regímenes políticos sino también acerca de la dinámica propia de estosúltimos y del lugar que en ellos tienen las elecciones.

En este sentido, el examen del caso venezolano podría desdoblarse en dos 
ámbitos. En el primero se identificarían las líneas rectoras dela experiencia venezolana y se apuntaría su problemática actual. En el segundo, se recogerían estos elementos con el propósito de inscribirlos en el contexto latinoamericano, no sólo como un ejercicio académico comparativo, sino por la urgencia práctica de extraer ciertas lecciones que, sin asumir su posible recurrencia en otros países de la región, permitan evaluar los problemas y opciones que existen ahora en el paso de una primera fase de transición de los regimenes autoritarios hacia gobiernos democráticos, a una segunda fase donde estaría en juego la consolidación de la democracia o, en términos de O'Donnell, "la vigencia efectiva de un régimen democrático". ${ }^{2}$

En estas notas nos concentramos en el primer ámbito. ${ }^{3}$ Debe advertirse además que las presentes páginas tienen un marcado caracter preliminar. Se trata, en efecto, de una primera aproximación al estudio del régimen político venezolano que, a su vez, forma parte de un proyecto de investigación más amplio que trata de comparar las relaciones entre los perfiles de renegociación de la deuda externa y los regímenes políticos de Brasil, México y Venezuela.

Presentamos primero ciertos datos mínimos que dan cuenta de los 30 años de experiencia electoral de Venezuela. En seguida, identificamos sus principales alcancesy limitaciones, para concluir con

${ }^{2}$ Guillermo O'Donell, "Transiciones, continuidades y algunas paradojas", Cuadernos Políticos, núm. 56, enero-abril de 1989, México, p. 20.

${ }^{3}$ Para un análisis de la transición venezolana de finales de los cincuenta que busque extraer específicamente lecciones para los actuales retos de los procesos de transición de la región, véase Daniel H. Levine, "The transition to democracy: are there lessons from Venezuela?", Bulletin of Latin American Research, vol. Iv, núm. 2, 1985, pp. 4761. el esbozo de algunas opciones para el futuro inmediato.

TREINTA AÑOS DE EXPERIENCIA ELECTORAL, 1958-1990: TRES INSTANTÁNEAS

De 1958 a 1990 Venezuela ha efectuado siete transferencias de gobiemo bajo un sistema electoral competitivo. En seguida presentamos los datos mínimosque conforman tres instantáneas que dan cuenta de esta evolución. Para comenzar conviene presentar a grandes rasgos las principales organizaciones políticas actuantes.

\section{Primera instantánea: los partidos politicos}

Acción Democrática (AD) es sin duda el más importante partido en el país. Fundado en 1941 porla línea reformista de la llamada generación del $28, \mathrm{AD}$ ha obtenido el poder cinco veces desde 1958. Su orientación política está muy cercana a la socialdemocracia aunque siempre bajo un tono más bien moderado. Su presencia en organizaciones laborales y campesinas, como la Confederación de Trabajadores de Venezuela (CTV) y la Confederación de Campesinos Venezolanos (CCV), le ha permitido conseguir buena parte de su clientela electoral en estos sectores.

El Comité de Organización Política Electoral Independiente (COPEI) fue creado en 1946 y recoge la herencia ideológica conservadora y demócrata-cristiana de la misma generación del 28. Posee tambiénuna influencia importante en movimientos sociales más amplios y en las confederaciones de trabajadores y de campesinos. COPEI ha sido el único partido capaz de alternar la presidencia

\section{1}


con AD-lo hizo en dos ocasiones-y conforma, junto con éste, el pilar del bipartidismo que de hecho ha predominado en la orientación electoral desde mediados de la década de los setenta.

La Unión Republicana Democrática (URD) representa una opción de centroizquierda que fue creada aprovechando el paréntesis del "trienio" y que tuvo cierta influencia en el mercado electoral durante 1958-68, misma que a partir de entonces ha perdido gradualmente. Su posterior presencia electoral se ha negociado, por lo general, bajo alianzas con partidos menores como el Frente Nacional Democrático (FND) y el Frente Democrático Popular (FDP).

El ala izquierda del abanico electoral está representada por una diversidad de partidos, tales como el Partido Comunista Venezolano (PCV), el Movimiento al Socialismo (MAS), el Movimiento Electoral del Pueblo (MEP),y el Movimiento de Izquierda Revolucionaria (MIR), entre otros. Su orientación ideológica es variada, lo mismo que su incidencia en los resultados electoralesy lasorganizaciones laborales de campesinos y trabajadores. Debe indicarse, además, que el MIR se originó en los sesenta, de una escisión de la izquierda joven de $\mathrm{AD}$, mientras que el MAS proviene de una división en el interior del PCV de principios de la década de los setenta

En torno a este horizonte de opciones se han desenvuelto las distintas jornadas electorales. Sus resultados han sido de manera general los que mencionaremos a continuación. ${ }^{4}$

\footnotetext{
${ }^{4}$ Los datos son de Levine, "Venezuela since 1958: the consolidation of democratic politics", en Juan J. Linz y Alfred Stepen (comps.), Tbe breakdown of democratic regimes, Latin America, The Johns Hopkins University Press, Baltimore, vol. III, p. 96, cuadro 2; y Rigoberto Lanz, "Venezuela: los limites de la democracia made in USA", en Lorenzo
}

Segunda instantänea: las jornadas electorales

En la primera jornada electoral, en 1958 , el candidato de $\mathrm{AD}$, Rómulo Betancourt, llegó a la presidencia con $49.2 \%$ de los sufragios, en tanto su más cercano competidor, de la URD, obtuvó $30.7 \%$, mientras el COPEI logró $15.7 \%$, siendo, por último, $3.2 \%$ de la votación para el PCV.

Para la segunda jornada, en 1963, el voto se orientó de nuevo en favor del candidato de AD, Raúl Leoni, pero en esta ocasión el margen de victoria fue mucho más reducido. De hecho, la distribución del voto ofreció un perfil más atomizado al otorgar $32.8 \%$ a $\mathrm{AD}, 20.2 \%$ a COPEI, $17.5 \%$ a URD, y $27.8 \%$ a candidatos diversos y heterogéneos que fueron promovidos por partidos y organizaciones sociales que se crearon al calor de la contienda electoral. ${ }^{5}$ La izquierda comunista no participó en estas elecciones tanto por su decisión de intentar el cambio social por la vía armada como por la gradual y eficaz marginación y represión de la que venía siendo sujeto por parte del Estado.

Para la tercera contienda electoral, en 1968 , se presentan dos novedades de importancia. La primera de ellas radica en que por vez primera en la historia del país, llega a la presidencia el candidato de un partido de oposición. Rafael Caldera, candidato de COCEI, obtuvo, en

Meyer y José Luis Reyna (coords.), Los sistemas políticos en América Latina, Siglo XXI Editores/ Universidad de las Naciones Unidas, México, 1989, pp. 220-224. Como se advertirá, sólo haremos referencia a los resultados de las votaciones presidenciales.

${ }^{5}$ Tales fueron los casos del escritor Arturo Uslar Pietri-quien fue apoyado por el FND-y del líder del gobierno provisional formado a la caída de Pérez Jiménez, Wolfgang Larrazábal, quien se presentó como candidato del FDP. 
efecto, $29 \%$ de los votos, en tanto $\mathrm{AD}$ consiguió $28.2 \%$, la URD, en alianza electoral con el FND y el FDP $22.2 \%$ y el $20.3 \%$ restante se distribuyó entre varios partidos de relativamente menor importancia, entre los que cabría mencionar el MEP, que obtuvo cerca de $3 \%$ de los votos.

El segundo elemento se refiere a dos procesos que afectaron directamente la participación de las fuerzas políticas de izquierda. Por un lado está la reincorporación de los partidos de izquierda, en especial el PCV, al sistema electoral después de una infructuosa y dolorosa experiencia guerrillera y, por el otro, el surgimiento de nuevas organizaciones políticas como producto de divisiones en $\mathrm{AD}$; tal fue el caso del MEP.

Para las elecciones de 1973, AD recuperó el poder en la figura deCarlos Andrés Pérez, obteniendo $48.8 \%$ de los votos-su nivel más alto desde 1958-mientras que COPEI alcanzó $36.8 \%$-paradójicamente también su nivel más alto desde 1958-. La URD, por su parte, obtuvo apenas $3 \%$ en tanto que la izquierda mostró un incremento en su votación al obtener $5.1 \%$ el MEP y $4.2 \%$ el MAS. El restante $2.1 \%$ se distribuyó entre partidos menores. Como se verá más adelante, estos resultados expresan lo quese ha denominado "elecciones críticas" porque representan una realineación en la orientación del votoen favor del bipartidismo. ${ }^{6}$

Las elecciones de 1978 testificaron el segundo periodo de acceso al poder para COPEI con la obtención de $45.6 \%$ de los votos para Luis Herrera Campins. AD

\footnotetext{
${ }^{6}$ Sobre el concepto de elecciones críticas y realineamientos sociopolíticos en América Latina puede consultarse, con gran cautela, a Howard Wiarda, "Critical elections and critical coups: the process of sociopolitical realignment in latin american development", en $\mathrm{H}$. Wiarda (comp.), The continuing struggle for democracy in Latin America, Westview Press, Boulder, 1980, pp. 27-69.
}

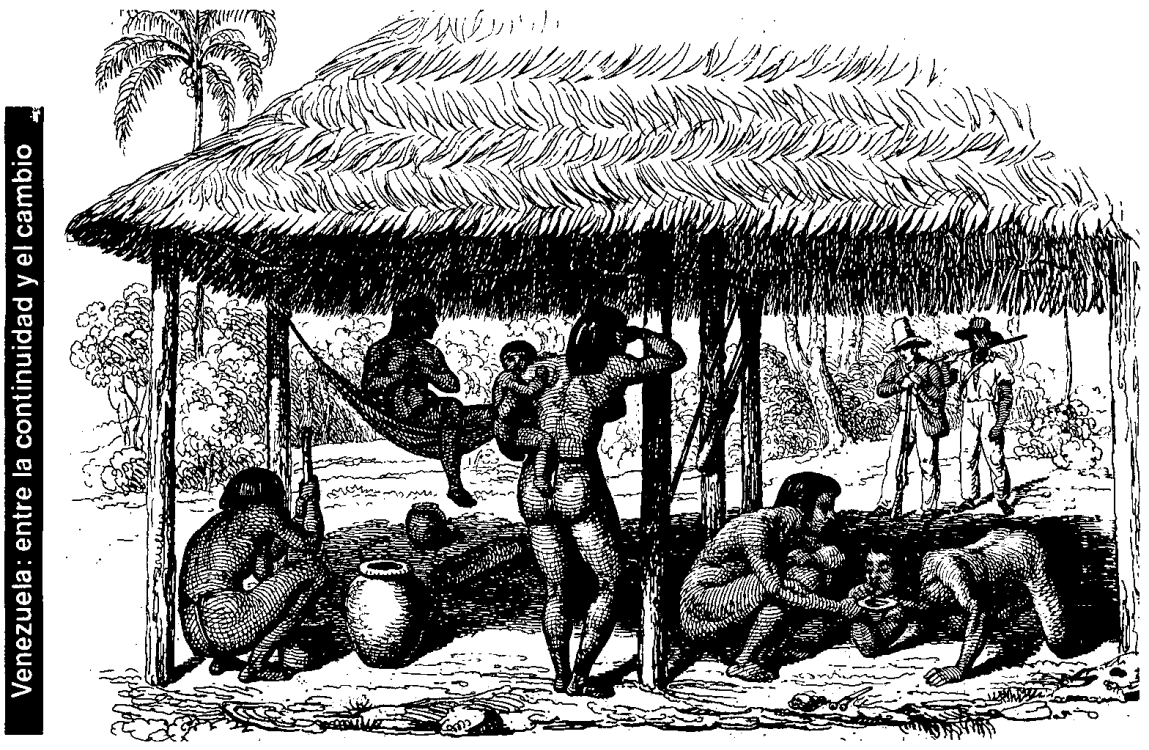


consiguió, por su parte, $43 \%$ mientras que la izquierda incrementó levemente su presencia electoral al alcanzar $13.5 \%$ y, finalmente, el $6 \%$ restante lo captó la URD.

En la sexta jornada, en 1983, se vuelve a dar una alternancia de poder al llegar a la presidencia el candidato de $\mathrm{AD}$, Jaime Lusinchi, quien con $55 \%$ de los votos superó las posibilidades, tanto de continuidad de COPEI -que logró $32.5 \%$ del sufragio-como las de fortalecimiento de la izquierda, que consiguió un nivel de votación inferior a la de la anterior contienda al lograr ahora 10\%. Debe resaltarse que URD sufrió su mayor descalabro al captar sólo $2.2 \%$ del voto, haciendo evidente así su paulatino debilitamiento como opción atractiva para el electorado.

Finalmente, las elecciones de 1989 permitieron observar no sólo la continuidad en el poder de $A D$, sino que a su vez produjeron la primera reelección presidencial por vía electoral desde 1958, al llevar de nuevo a Carlos Andrés Pérez a la presidencia. La distribución de votos fue muy similar a la observada en las últimas elecciones.

\section{Tercera instantánea: características y atributos}

Este registro mínimo de la evolución de las elecciones presidenciales nos lleva a distinguir cuatro características del sistema electoral venezolano:

Continuidad. Treinta años consecutivos de elecciones efectivamente competitivas representan ciertamente algo novedoso en la historia política de Venezuela, y no es, por lo demás, un registro que pueda encontrarse fácilmente en otros países de la región.

Estabilidad. Esta continuidad electoral ha sido una de las causas, a la vez que una expresión, de la estabilidad política del país.

Pluralidad. Este perfil de continuidad electoral y de estabilidad política maximizó el papel que los partidos políticos tienen en el régimen político. Esto permitió la formación de un horizonte de articulación de la vida política donde se privilegia a los partidos políticos como los espacios sociales más eficientes y dinámicos para administrar institucionalmente el conflicto social. Básicamente, en el ámbito partidista se han gestionado y negociado los intereses de las diferentes clases sociales y se ha propiciado el encuentro de las pasiones y vocaciones ideológicas. Ello, a su vez, fomentó la conformación de un pluralismo de opciones electorales que sigue vigente a pesar del fuerte énfasis bipartidista de la última década.

Legitimidad. Las elecciones fueron adquiriendo legitimidad no sólo como procedimiento sino también como forma de relación entre Estado y sociedad. La legitimidad de las elecciones se trasladó al régimen político del que forman parte.

Continuidad, estabilidad, pluralidad y legitimidad son entonces los rasgos básicos sobre los cuales se ha desarrollado el sistema electoral del país en las tres últimas décadas. Debe indicarse, además, que estas características están complementadas por la naturaleza competitiva de las elecciones. La edificación del sistema electoral, en efecto, fue adquiriendo gradualmente atributos que se han identificado como propios de las elecciones competitivas. Así, el sistema electoral descansa en cuatro premisas referidas al sufragio: es universal en cuanto a la extensión del derecho a voto, directo, ya que su emisión ńo tiene intermediarioso está fragmentado, libre, en el sentido de que no está sujeto a coerción o presión externa manifiesta para expresarsu orien- 
tación, y efectivo, en cuanto es obvio que no será sujeto de fraude.?

Es probable que sin este perfil efectivamente competitivo, el papel de las elecciones en la dinámica política hubiese sido otro y que sus cuatro características básicas -continuidad, estabilidad, pluralismo y legitimidad-no estuviesen presentes.

Ahora bien, estas características y el perfil competitivo del sistema electoral no dan cuenta por si mismos ni del conjunto de problemas y contradicciones que han caracterizado al régimen político venezolano ni de la lógica política que lo ha vuelto dinámico. Para ello, debemos observar el papel que el sistema electoral ha tenido en el desarrollo del ciclo político de la "democracia pactada", con el propósito de advertir sus alcances y limitaciones.

Así, identificaremos tres etapas en este ciclo: 1) transición, 2) consolidación y 3) disyuntiva crítica entre cambio o continuidad. El siguiente apartado está dedicado a este problema.

\section{ALCANCES Y LIMITACIONES DE UN CICLO DE DEMOCRACIA PACTADA}

De acuerdo con el ejercicio de clasificación que Stepen ha realizado con relación a las vías de redemocratización de los regímenes políticos, la experiencia venezolana correspondería a una transición de pacto de partidos con elementos concesionales. ${ }^{8}$ En efecto, el ciclo de

\footnotetext{
${ }^{7}$ Este perfil de las elecciones competitivas está desarrollado en Guy Hermet, "Las elecciones en los regímenes autoritarios: bosquejo de un marco de análisis", en G. Hermet, Alain Rouquié y Juan J. Linz (comps.), ¿Para qué sirven las elecciones?, Fondo de Cultura Económica, México, 1986, pp. 20-32.

${ }^{8}$ En sentido estricto más que redemocratización
}

democracia política que se abre en 1958 y que llega hasta la actual década, fue edificado a partir de lo que Stepen ha distinguido como: "La construcción interna de un gran acuerdo opositor, posiblemente con algunos elementos concesionales. Los miembros del pacto seunen para derrocar el régimen autoritario y sentar las bases para un subsecuente régimen democrático en el cual el poder está abierto a la mayoría de las fuerzas opositoras."

Ello es particularmente importante en la primera etapa del ciclo político de democratización, que conviene designar como de transición.

El mismoStepen indica que la creación de este tipo de pactos enfrenta inmediatamente la búsqueda de su mantenimiento o consolidación. Este segundo proceso por lo general se basa en dos instancias: por un lado, en la capacidad ideológica y organizativa de los distintos líderes involucrados para seguir negociando por un tiempo significativo dentro del régimen creado y, por el otro, en la lealtad o aceptación de sus seguidores políticos a los términos del pacto. Esta segunda etapa del ciclo político la denominaremos de consolidación y está caracterizada por la vigencia de los términos del pacto.

convendría hablar, para el caso venezolano, de democratización ya que el prefijo implicaría la existencia previa de un régimen democrático que por alguna razón ha dejado de ser vigente. En el caso venezolano, aunconsiderandola transitoria época del "trienio", no existía tal régimen sino la necesidad de construirlo.

${ }^{9}$ Alfred Stepen, "Paths towards redemocratization: theoretical and comparative considerations", en Guillermo O'Donell, Philippe D. Schmitter y Laurence Whitehead (comps.), Transition from authoritarian rule. Comparative perspectives, Johns Hopkins University Press, Baltimore, 1986, p. 79. 
La tercera etapa del ciclo se caracteriza por la emergencia de tensiones en el funcionamiento del acuerdo, de tal modo que se va generando un momento político en que el acuerdo original se enfrenta a una suerte de encrucijada entre el cambio o la continuidad. Estas tensiones pueden provenir lo mismo de las instancias políticas institucionalizadas en el régimen político, que de espacios y actores sociales no institucionalizados. La encrucijada frente a la que se encuentra el régimen abre el camino a diferentes opciones. A esta tercera etapa del ciclo la identificaremos como la etapa de crisis del ciclo político de la democracia pactada.

Aunque esta suerte de secuencia del ciclo político no guarda necesariamente una correspondencia directa y lineal con los calendarios y coyunturas electorales, éstas, por su perfil competitivo y su lugar estratégico en la estabilidad y legitimidad del régimen del que forman parte, sí inciden tanto como en los ritmos, como en la orientación y la profundidad del ciclo político. Con base en esto último y siguiendo la periodización señalada, se procurará en seguida esbozar los alcances y límites del ciclo político venezolano de 1958 hasta el presente.

Al abandonar el país el general Marcos Pérez Jiménez el 23 de enero de 1958, Venezuela se encontraba en un momento político que favorecía un ritmo más o menos expedito de transición hacia un gobierno democrático. Esta situación no se dio por generación espontánea sino que representó el cierre de un largo ciclo histórico en la vida política y económica del país y la apertura hacia un nuevo ciclo en las modalidades de su vida política.

A lo largo de este ciclo, que de manera un tanto arbitraria podemos decir que ocupa toda la primera mitad del presente siglo, ${ }^{10}$ se alteró de manera fundamental el perfil socioeconómico del país, aunque ciertamente a un ritmo menor que en otros países de la región. ${ }^{11}$ Se trata de una serie de alteraciones múltiples de las cuales queremos resaltar tres.

En primer lugar, destaca el gradual peroirreversible proceso deurbanización de la población. Si en 1936 cerca de un tercio $(28.9 \%)$ de la población era urbana, para 1961 ésta representaba dos tercios del total de habitantes $(62.5 \%))^{12}$ Las bases tradicionales del soporte político de la alianza oligárquica entre terratenientes y militares fueron debilitándose cuantitativa y cualitativamente al alterarse poco a poco tanto las bases materiales en que se desenvolvían la reproducción de las clases sociales tradicionales como el complejo sistema de lealtades y alianzas políticas que estas clases sostenían.

En segundo lugar, esta urbanización de la población reflejaba, en cierta manera, una tendencia a la urbanización de

${ }^{10}$ El ciclo se iniciaría en 1908 con la dictadura militar de Juan Vicente Gómez, continuaría con los regimenes militares de López Contreras y Medina Angarita (1935-45) y culminaría con los años de Pérez Jiménez (1948-58), después del paréntesis del "trienio" (1945-48).

${ }^{11}$ Para un análisis detallado de la trayectoria económica y demográfica quecubre hasta la década de los setenta, véanse los artículos de Malavé Mata, Orta, Araujo, Maza Zavala y Bolívar Chollet reunidos en el libro Venezuela. Crecimiento sin desarrollo, Nuestro Tiempo/Universidad Central de Venezuela, Mêxico, 1980, así como el ensayo de De la Plaza ya citado. Para una revisión más actualizada que presenta las expecta tivas para el futuro inmediato, consúltense los ensayos de Yañes y Haussman que aparecen en Silvia Michelena (coord.), Venezuela bacia el año 2000. Desafiosy opciones, Nueva Sociedad, Caracas, 1987.

${ }^{12}$ Miguel Bolívar Chollet, "El comportamiento demográfico en el subdesarrollo: el caso venezolano", en D.F. Maza Zavala etal., Venezuela. Crecimiento sin desarrollo, op. cit., p. 369. 
las actividades económicas que, sin embargo, no implicaba necesariamente ni su modernización plena ni una diversificación extensa. De hecho, el sector predominante de generación de excedente económico se concentró en la renta petrolera, al mismo tiempo que se daba una hipertrofia en los sectores de servicios y financiero. Esta importancia dela renta petrolera como incentivo para la urbanización queda destacada por tres hechos.

Por un lado, la alta disponibilidad de divisas permitió sostener una continua sobrevaluación de la moneda nacional que erosionó continuamente la competitividad internacional de ciertos productos primarios de exportación y volvió más atractiva la importación de alimentos que su producción local. Así, la actividad agrícola, tanto la volcada al mercado internacional como la dirigida al mercado interno, fue disminuyendo su atractivo como oportunidad de inversión y como fuente de empleo.

Por otro lado, en relación con la actividad petrolera o con sectores articulados con ella, fue desarrollándose poco a poco una industria local que fomentó el crecimiento de la clase obrera y de sectores mediosque, con el paso del tiempo, aumentarían su relevancia económica (bases para el mercado interno) y política (bases para un redefinición de los agentes políticos y del realineamiento de las lealtades). Con todo, debe agregarse que el efecto de esta expansión urbano-industrial fue menospronunciado que la recesión observada en el sector rural. De nuevo la disponibilidad de divisas permitió absorber los efectos de la crisis de los treinta inhibiendo el inicio del proceso de sustitución de importaciones, que no arranca de manera plena sino hasta después de la segunda guerra mundial.
En tercer término, la petrolización de la economía representó en gran medida la petrolización del ingreso fiscal del Estado. Si para 1917 el ingreso petrolero captado por el Estado representaba apenas $0.2 \%$ del ingreso total de éste, para 1935 llegó a $29.2 \%$, a $57.7 \%$ en 1958 y a $54.5 \%$ para $1963 .{ }^{13}$ Esta fuerte asociación al ciclo de los mercados internacionales del petróleo creó una suerte de "petrolización" de la toma de decisiones del Estado.

Sin embargo, más que canalizar estos recursos hacia la actividad económica o hacia una distribución del ingreso, los regímenes militares -de Vicente Gómez (1908-35) a Pérez Jiménez (1948-58) pasando por las administraciones militares (1935-45)- procuraron fortalecer la capacidad política y de cohesión del Estado ya que se orientaron básicamente hacia la centralización del poder político (ruptura con el caudillismo regionalista previo), la profesionalización de las fuerzas armadas y la ampliación de la base administrativo-burocrática del Estado. ${ }^{1 i ́}$

Paralelamente a las tensiones que generaba el proceso de cambio en el perfil socioeconómico de la población y de la estructura económica, se fue presentando una alteración en el ámbito político que no era susceptible de canalizarse por medio de los mecanismos tradicionales con que venía funcionando el Estado. Esta alteración se expresaba tanto entre los agentes sociales portadores de demandas e intereses políticos como en el contenido de las expectativas de participación y organización política de estos agentes.

${ }^{13}$ Charles Bergquist, Labor in Latin America. Comparative essays on Cbile, Argentina, Venezuela and Colombia. Stanford University Press, Stanford, 1986, p. 209.

${ }^{14}$ Manuel Caballero, Las Venezuelas del siglo $x x$, Grijalbo, Caracas, 1988. 


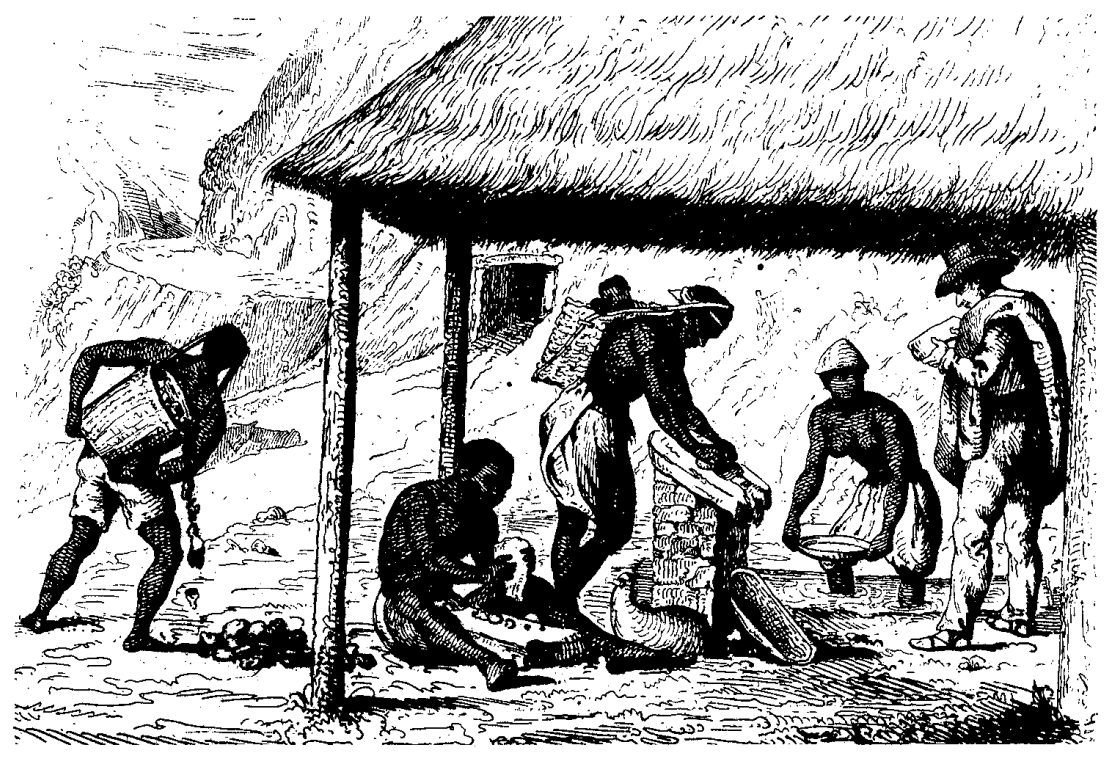

Así, más que correlato de una crisis económica o de una irrupción violenta de las clases sociales, el debilitamiento del régimen político militar se asoció al dinamismo de las transformaciones estructurales procesadas a lo largo de varias décadas y a la emergencia de claras demandas de participación y organización política. Como ha anotado Lanz: "El derrocamiento de la dictadura perezjimenista no es el punto de llegada de una aguda crisis socioeconómica, sino la explosión de demandas políticas inviables en el marco de un régimen brutal, corrupto y sin proyecto político real." ${ }^{\prime 15}$

\footnotetext{
${ }^{15}$ Lanz, op. cit., p. 218. Desde una perspectiva analítica distinta Terry Lynn Karl ha expresado: "En este contexto, el crecimiento y transformación de la Venezuela urbana sirvió de campo fértil a un régimen democrático reformista", "Petroleum and political pacts: the transition to democracy in Venezuela", en Guillermo O'Donell et al., op. cit., p. 201.
}

Se presentó con esto una suerte de vacío entre Estado y sociedad que llevaría a lo que Cammack ha denominado "crisis de capacidad política de la clase dominante". ${ }^{16}$

Esta suerte de vacío exigía la restauración de los vínculos entre sociedad y Estado, con lo que se abrieron las puertas para que la vía de transición con más probabilidades de presentarse fuese la de democracia pactada y concesional.

La naturaleza pactada de la transición se dio tomando como instancias de gestión las organizaciones políticas y sindicales que se habían formado desde 1935, en especial durante el "tiienio". Estas organizaciones de hecho habían empezado a influir en todo el tejido social de la época pero carecían del marco insti-

${ }^{16}$ Paul Cammack, "Democratization: a review of the issues", Bulletin of Latin American Research, vol. Iv, núm. 2, 1985, p. 39. 
tucional y legal para su expresión y crecimiento. Aun así, los actores y líderes sociales emergentes no esperaron la salida del dictador Pérez Jiménez para ir definiendo, negociando y pactando los alcances y límites de las normas y procedimientos que estaban dispuestos a aceptar una vez que los militares abandonasen el poder. De hecho, su participación política estaba amparada poruna experiencia generacional (de 1928 a 1958) $y$, de manera significativa, por el laboratorio político que representó el "trienio" $1945-48 .{ }^{17}$

Debe resaltarse que el pacto político de transición fue posible especialmente por la vía de los partidos políticos y la incorporación masiva de sectores sociales a la vida política. De este modo, la transición pactada fue resultado tanto de la disposición política de elites partidarias como de la revitalización de los partidos políticos de masa ya existentes. Tal situación haría dinámica la búsqueda de vías institucionales para la solución del conflicto social por medio de los partidos políticos pactantes y las asociaciones laborales y sindicales asociadas a éstos. ${ }^{18}$

${ }^{17}$ No toca analizar aquí con detalle estos años, ni las vicisitudes de las negociaciones entre los sectores de oposición al régimen militar de 1948 a 1958. Al respecto, véanse Levine ("Venezuela since $1958 . . . " \mathrm{y}$ "The transition...") y Lynn (op. cit.), quienes han ofrecido excelentes análisis. Sólo quisiéramos indicar que el "trienio" presenció el establecimiento del sufragio universal y directo y la creación del COPEI y la URD.

${ }^{18} \mathrm{La}$ importancia de la integración de las grandes organizaciones laborales a la vida politica del país, en especial por medio de ACD y COPEI, ha sido resaltada por Francisco Zapata en los siguientes términos: "la historia contemporânea del conflicto laboral en Venezuela coincide con los procesos de democratización, ligados a la sindicalización de sectores obreros... A diferencia de otros países, el desarrollo del sindicalismo en Venezuela es inseparable de la consolidación de un régimen
Esta institucionalización se fundamentó en dos tipos de acuerdos, que en su conjunto conformaron un verdadero acuerdo nacional tendiente a industrializar y democratizar el país. Los acuerdos de naturaleza económica se materializaron en "La declaración de principios y de un programa mínimo de gobiemo" y en el "Pacto de avenimiento obrero-patronal" (abril de 1958). Basándose en ellosse fijaron tres compromisos; en principio, el de otorgar al Estado un papel central en la promoción del desarrollo económico, mismo que estaría dinamizado por la acumulación privada; en seguida se fijố un marco de moderación y de concertación institucional para el sector laboral que no obstaculizara la generación de inversión y qụe, a su vez, apoyara la estabilidad política; finalmente, se delineó un esquema de relativa distribución del ingreso que evitara la polarización social y ampliara el mercado interno.

Por su parte, los acuerdos de tipo político se sintetizaron en el "Acuerdo de pacto fijo" (octubre de 1958) que establecía, en lo básico, cuatro elementos: el reconocimiento de la legitimidad de las diferencias políticas, la creación de un programa común en relación con la modernización económica, la formación de coaliciones partidistas de gobierno, y la defensa compartida de un régimen político democrático.

Con respecto a esto último, es pertinente subrayar que bajo este pacto político en favor de una intensa y renovada vida partidaria y de una institucionalización del conflicto social, el sistema electoral apareció como un procedimiento privilegiado para trazar el nuevo

democrático", El conflicto sindical en América Latina, El Colegiode México, México, 1986, p. 141. 
espacio social de la negociación y el acceso a la toma de decisiones colectivas. Así, esta primera fase del nuevo ciclo político representó también, y de manera fundamental, la creación de un sistema electoral competitivo.

El sistema electoral competitivo proporcionódos factores esenciales a la etapa de transición del nuevo régimen: por un lado normas y procedimientos aceptados por los líderes políticos y acatados por sus seguidores para establecer "quién está autorizado para tomar las decisiones colectivas y bajo qué procedimientos", ${ }^{19}$ y por el otro un abanico institucional para lograr la continuidad y estabilidad política del régimen.

Ahora bien, la segunda característica de la transición pactada son los elementos consensuales explícitos e implícitos sobre los que se hicieron viables desdela perspectiva de las pactantes, los acuerdos económicos y políticos. Estos elementos consensuales se refieren en lo fundamental a los criterios de supervivencia del proceso de transición. Éstos se definieron, a su vez, tanto en el ámbito económico como en el político. Con relación al primero, se moderaron al máximo las aspiraciones de reforma económica que ciertos sectores, en especial los grupos de izquierda de AD y los sindicatos laborales y agrarios, consideraban como necesarias no sólo por criterios de justicia económica sino también como parte de la modernización económica. Esta moderación, un verdadero giro del reformismo progresista del "trienio" hacia un reformismo conservador, afectó especialmente los alcances de la reforma agraria y la evolución de los salarios reales urbanos.

\footnotetext{
${ }^{19}$ Norberto Bobbio, El futuro de la democracia, FCE, México, 1986, p. 14.
}

En relación con el ámbito político, se dio algo más que un estrechamiento del abanico de partidos políticos, ya que no sólo se excluyó y marginó a los partidos de izquierda del nuevo régimen político -después, por cierto, de participar activa y decididamente en el derrocamiento de Pérez Jiménez-sino que se dio una purga en el interior de los partidos políticos dominantes, AD y COPEI, de sus elementos más radicales. Una suerte de anticomunismo elemental, muy propio del inicio de la guerra fría, combinado con una sensación desmedida de "amenaza" a la democracia llevó a que estos partidos, junto con sectores empresariales y religiosos, suscribieran esta lógica de exclusión.

Ello, aparejado a las expectativas creadas por los cambios políticos ocurridos en Cuba, llevó a la clandestinidad y a la guerrilla al PCV y al MIR que crearon el Frente de Liberación Nacional-Fuerzas Armadas de Liberación Nacional (FLNFALN), organización de carácter políticomilitar.

Bajo este ambiente creado por el reformismo económico moderado y de participación política selectiva, tienen lugar las dos primeras jornadas electorales. Considerando esta fase de transición como parte de un ciclo político y socioeconómico más amplio, puede afirmarse que su importancia en el terreno económico fue menos relevante que en el área política. Aquí hay que resaltar el hecho de que la renta petrolera se convirtió en una vía fiscal asociada más a una lógica de legitimación (distribución relativa del ingreso) que a una lógica de acumulación y diversificación del capital. Fue necesario que el petróleo subsidiara la estabilidad política del periodo de transición debido a la insuficiencia y moderación delas reformas ecónomicas; no quiere decir que no se profundizara el 
crecimiento económico pero sí indica que los niveles de desarrollo estuvieron muy por debajo, tanto de las expectativas oficiales, como de las que se hubiese podido esperar dado el excedente generado por el sector petrolero.

Así, de esta amalgama entre elementos de pacto y de consenso de elites y moderación económica, se constituyeron los alcances y limitaciones del nuevo régimen político. Sobre estos factores se transitaría a la etapa de consolidación donde se observaría con mayor nitidez sus alcances y limitaciones.

- De 1968 a finales de la década de los setenta se observa una vigencia más plena del pacto democratizador al llegarse a la consolidación del régimen político. En estos años no sólo se inaugura la alternancia efectiva del poder bajo elecciones competitivas sino que también se presenta la reincorporarción de la izquierda a las vías legales de participación política. Paralelamente, el proceso económico ingresaría a una etapa de expansión como efecto de la modernización y transnacio- nalización de la estructura productiva y de la inyección de capital que propició el primer boom petrolero de 1973.

El régimen político propiciaba ya un mayor ambiente de certidumbre que facilitó la continuidad institucional de las negociaciones entre las organizaciones políticas, sindicales y empresariales. Igualmente las bases sociales de estas agrupaciones no manifestaron una predisposición para contravenir los términos de negociación que se les ofrecian, antes bien procuraban capitalizarlos por diferentes medios y por diversos objetivos.

Al respecto es particularmente notoria la capacidad de los mecanismos para cubrir institucionalmente los conflictos laborales y darles, incluso, un manejo partidista muy evidente en las coyunturas electorales. ${ }^{20}$

Como consecuencia, se incrementó la centralidad de los partidos en la vida política, sólo que esto en vez de acentuar

${ }^{20}$ Zapata, op. cit.; Bergquist, op. cit.

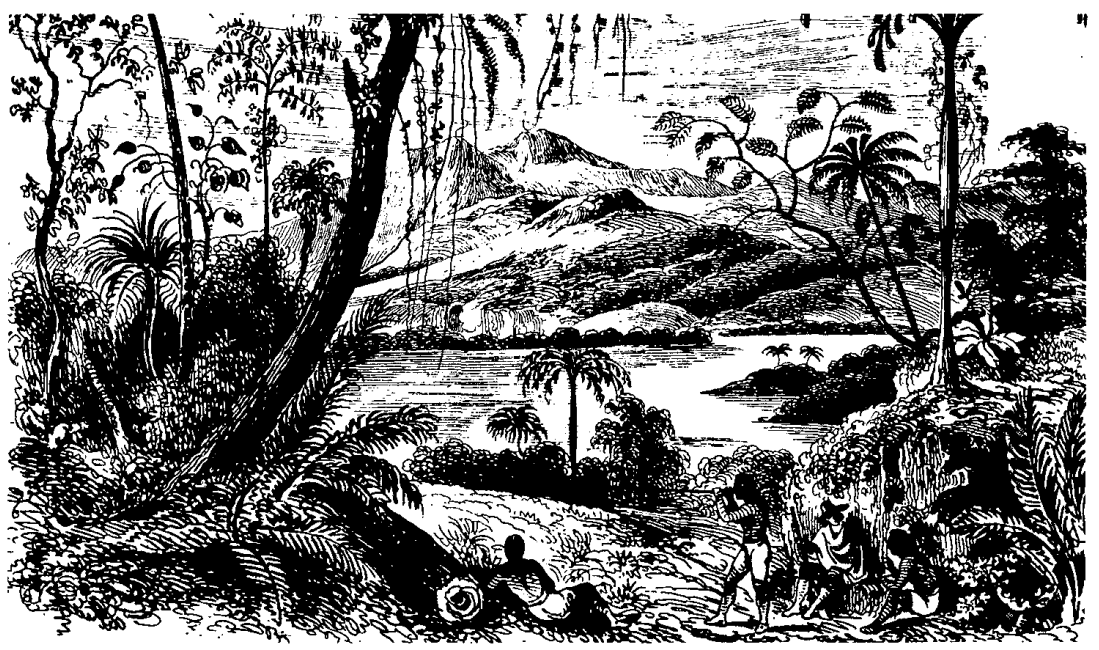


el pluralismo electoral fue fortaleciendo la estructura bipartidista en la orientación del voto; al mismo tiempo que sancionaba al binomio AD-COPEI como partidos hegemónicos, desplazó gradualmente a opciones como URD y estancó, después de un modesto incremento, la participación electoral de los partidos de izquierda.

A este realineamiento electoral no fue ajena la creciente concentración del excedente económico en manos del Estado, derivada en gran parte de la nacionalización petrolera. En un país en que el Estado administra una proporción tan importante del excedente económico y es responsable de una parte sustancial de la generación de empleo, no sorprende que las preferencias electorales se orientasen más a sancionar la gestión pública y la distribución sectorial que hiciesen de dichos recursos los partidos que se alternaban efectivamente en el poder, que a apoyar opciones quizá más atractivas ideológicamente pero con escasa viabilidad para acceder al poder ejecutivo. Lanz lo señala adecuadamente:

La lógica del bipartidismo opera no sólo como una distribución del mercado electoral en proporción a la fuerza coyuntural de cada agrupación, sino como un componente ideológico del comportamiento electoral de las clases y sectores dominados [ya que] los espacios políticos son ocupados según la preeminencia de esas fuerzas que han jugado la combinación del ejercicio del gobierno y la "oposición" en forma eficaz. ${ }^{21}$

Esto propició una extensión material para el ejercicio clientelista entre Estado, partidos políticos dominantes y sectores sociales, que tendió a debilitar el mercado electoral de los partidos sin quebrar

${ }^{21}$ Lanz, op. cit., p. 226. el bipartidismo. El estancamiento de los partidos de izquierda en niveles de votación queno rebasaron $13 \%$ y la paulatina desaparición del URD del mercado electoral son expresiones de ello.

Así, la consolidación de la democracia política tuvo un efecto de fortalecimiento del bipartidismo que, sólo en apariencia es paradójico: la vigencia del pacto representó la vigencia de sus alcances -institucionalidad, legitimidad, transparencia electoral, estabilidad- pero también la aparición de sus límites -un espacio de negociación filtrado casi exclusivamente por los partidos políticos dominantes, expansión del clientelismo pragmático, descrédito de opciones electorales alternativas, etcétera.

Por su propia evolución el régimen político comenzóa manifestar con mayor nitidez sus límites. Cierto que en estos años no se pone a discusión la continuidad del pacto democrático, pero sí se generaron las condiciones para que este cuestionamiento sea más evidente a finales de los setenta y a lo largo de todos los ochenta. El ciclo político enfrenta una disyuntiva.

Como quedó anotado, las tensiones de la democracia pactada comenzaron a desarrollarse, en parte porque fue alcanzando sus límites. Debe agregarse que la evolución de las contradicciones económicas estructurales, ejemplificada dramáticamente con el advenimiento de la crisis de los ochenta, intervino en la conformación de un ambiente de tensiones que afectó el ciclo político. La combinación de ambos elementos llevó al régimen político a la disyuntiva de cambio o continuidad en sus normas de funcionamiento. Quisiéramos destacar dos ámbitos que ilustran esta problemática.

El primero se refiere a las tensiones que se presentan dentro del régimen 


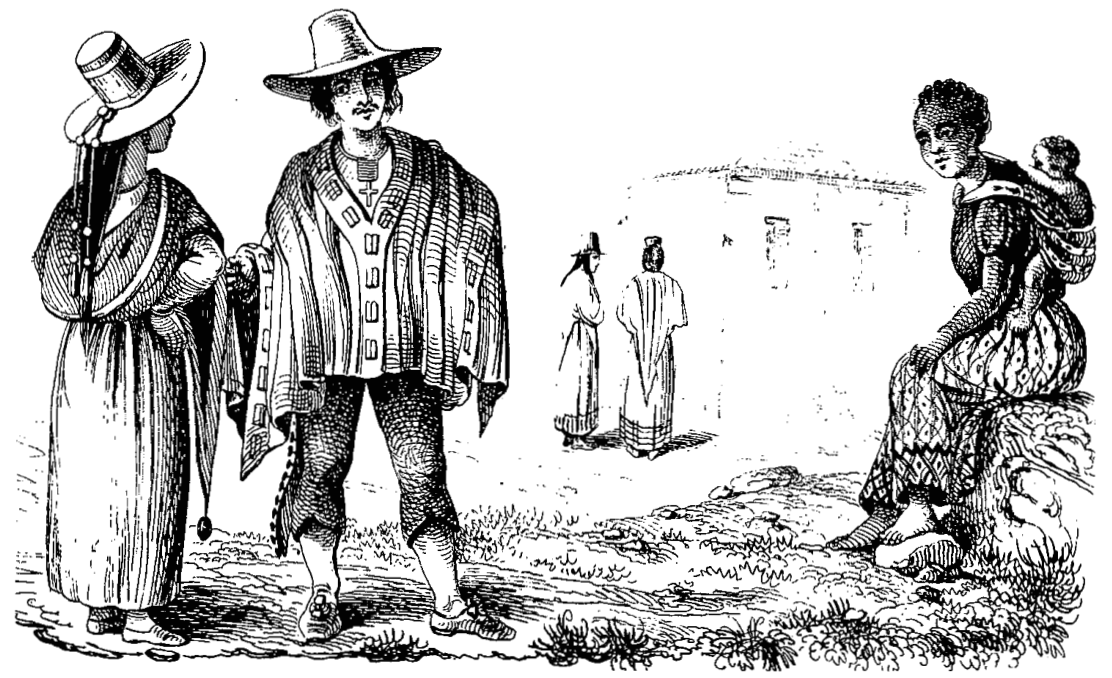

institucionalizado. Debeconsiderarseque el siginificativo crecimiento que desde mediados de la década de los setenta experimentó el Estado en su participación económica directa, es decir, como empleador y productor, complicó de manera significativa sus vínculos con el conjunto de la economía nacional e internacional.

La confusión estuvo acompañada de una gradual pero persistente alteración en las formas en que las elites perciben la gestión económica del Estado. Este cambio, acelerado por la crisis, ha favorecido una perspectiva cada vez más orientada a optimizar en términos económicos dicha gestión y a derivar parte de la legitimización estatal de la eficiencia y difusión de dicha optimización.

Sin embargo, esta suerte de tecnocratización del Estado parece ir a contracorriente de las tendencias que hicieron dinámico y consolidaron el sistema político, lo cual es patente en tres factores. ${ }^{22}$ Para comenzar, porque bajo esta tecnocratización se procura reducir el nivel de recursos de que dispone la burocracia política tradicional para el mantenimiento de relaciones clientelistas y el intercambio de lealtades políticas. Ello implica que la posibilidad de mantener estos acuerdos en el marco institucional está cada vez más asociada a una escasez de recursos que dificulta la posibilidad de solventar sus costos. Así, parece gestarse un desajuste entre las expectativas de continuidad de tales acuerdos y la base material que los hace posibles.

${ }^{22}$ Aquí seguimos de cerca los análisis de Luis Gómez Calcaño, "Estadoy clases sociales en Venezuela (1958-1981)", en Juan Enrique Vega (coord.), Teoría y política en América Latina, CIDE, México, pp. 251-268; y de Lynn, op. cit. 
En segundo lugar, porque al incrementarse los recursos bajo control de la tecnocracia y el manejo a discreción de éstos, se amplía la brecha entre el control parlamentario que supone el orden constitucional y el ejercicio económico por parte del ejecutivo y los grupos tecnócratas.

Finalmente, esta tecnocratización del cálculo del quehacer económico del Estado se difunde al conjunto de la economía del país, de tal modo que fomenta un desplazamiento de los componentes políticosde la economía en favor de una pretendida neutralidad y eficiencia del mercado en lo que corresponde tanto a la asignación de recursos como a la distribución funcional e institucional del ingreso.

Estos elementos promueven un relativo alejamiento entre la administración gubernamental y los partidos políticos que tiende a desvalorizar no sólo a estos últimos sino a las prácticas políticas asociadas a ellos, como son las elecciones, las movilizaciones de masas, la producción de ideologías o la gestión sectorial de intereses. Esta desvalorización en determinado momento se traslada al sistema electoral de modo tal que el bipartidismo existente lleva la contienda partidista a la inercia.

La supuesta despolitización y tecnocratización dela gestión económica tiende así a afectar las relaciones entre partidos, gobierno y sectores sociales de tal modo que devalúa las vías tradicionales sobre las que se sostienen tales relaciones. Así se promovería la búsqueda de caminos no electorales, pero "leales" al sistema, para el levantamiento de demandas, como son los grupos de presión.

Estos elementos están ya presentes desde mediados de la década de los setenta perose han acentuado en los ochenta con la intensidad y duración de la crisis económica. Por ahora no es posible afirmar que estas tendencias hayan madurado del todo pero debe apuntarse que su incidencia afecta ya al pacto político generado hace 30 años.

El segundo ámbito al que debe hacerse referencia alude a la emergencia de espacios de lucha política y social que no forman parte integral de las instituciones políticas vigentes. De manera general conforman lo que se ha dado en llamar, ambiguamente, los nuevos movimientos sociales y que representan la constitución de una democracia emergente. ${ }^{23}$

De acuerdo con Gómez Calcaño, estos movimientos sociales no tradicionales surgen como un resultado de las limitaciones de la democracia pactada, es decir, emergen como sectores sociales con demandas políticas, económicas y culturales no previstas en el pacto original y que, sin embargo, presionan constantemente a éste directa e indirectamente. Dado que no es fácil su incorporación institucional, la sola existencia de esta serie de presiones y demandas crea una brecha entre las expectativas y necesidades de estos sectores y la capacidad del Estado y los partidos políticos tradicionales para gestionarlas. Por lo demás, el fuerte énfasis de autonomía que al parecer reclaman estos movimientos, realza las dificultades para una coexistencia entre esta democracia emergente y la democracia tradicional.

El desarrollo paralelo de estas problemáticas en el "interior" y "exterior" del marco institucional vigente ha abierto un periodo de redefinición política del cual es dable esperarsi nola resolución desus dilemas, sí su gestión a partir de una

${ }^{23}$ Luis Gómez Calcaño, "Los movimientos sociales: democracia emergente en el sistema político venezolano", en Silvia Michelena (coord.), op. cil., pp. 337-367. 
disyuntiva, del cambio o de la continuidad. El mismo gobierno ya lo ha reconocido así y creó, en 1984, la Comisión Presidencial para la Reforma del Estado que se orientó a la introducción de una serie de reformas institucionales y administrativas que den flexibilidad al acuerdo democrático y lo encaucen hacia un nuevo periodo de estabilidad.

Debe reconocerse, sin embargo, que en esta ocasión la revigorización del pacto democrático no dependerá solamente de la capacidad de negociación de las elites sino también de la capacidad de la sociedad civil para fortalecer la democracia política por medio de la democratización del conjunto de la vida social del país. Acaso se transite de una democracia pactada y consensual a una democracia integral, pero ello no es más que un escenario posible; junto a éste existen algunos otros menos promisorios.

\section{ESPECULAACIONES SOBRE LAS OPCIONES PARA EL FUTURO INMEDIATO}

El momento político que enfrenta actualmente Venezuela abre el camino para tres opciones de solución de su crisis: continuidad, cambio y autoritarismo. Bajo la primera se intenta dotar de nuevo aliento al pacto original sin que se conduzca a una alteración fundamental de sus términos (opción de continuidad). La segunda procuraría la conformación de un nuevo pacto que redefiniera los alcances y límites del quehacer político nacional (opción de cambio). Porúltimo, la tercera vía conduciría a un ruptura que reinstauraría el autoritarismo con independencia de su forma -militar o civil-y vocación ideológica (opción autoritaria).

Con respecto a las perspectivas hay que advertir en primer lugar que no se piensa que cada una de estas opciones pueda darse en forma pura. De hecho parece más pertinente considerar una posible combinación entre éstas.

Así, por ejemplo, la opción de continuidad podría combinarse con ciertos elementos de la opción autoritaria o de la opción de cambio. La primera de estas combinaciones podría darse si prevalece la rigidez del régimen. Esta vía no haría sino incrementar las tensiones políticas y quizá, en el mediano plazo, podría llevar a una regresión y reinstauración del autoritarismo. Por ahora no está claro si éste adquiriría una forma militarizada o civil con respaldo militar o, para utilizar la expresión de O'Donnell, de "democradura" ${ }^{24}$ En cualquier caso, el sistema electoral estaría sujeto a una fuerte redefinición en donde no sorprendería quese debilitaran algunos de sus atributos competitivos -lo que induciría a un debilitamiento de su papel en la dinámica política-o que a la larga se cancelara.

Si la opción de continuidad se da bajo un marco de flexibilidad, es posible que haya una suerte de "continuidad con cambio", que a su vez podría ampliar los niveles de democratización del sistema político, con lo que el sistema electoral fortalecería su carácter competitivo y su relevancia. Es posible incluso que tal situación lleve a una realineación de la orientación del voto que permita superar el actual bipartidismo, pero, debemos agregar, quizá sólo se produciría al mediano plazo.

Otro escenario resultaría si predomina la opción de cambio y que ésta se combine con cierto grado de continuidad. De la continuidad se esperaría la permanencia de las características competitivas del sistema electoral y las bases institucionales para dirimir el conflicto social; así se retendría la aportación de

${ }^{24}$ O'Donell, op. cit. 


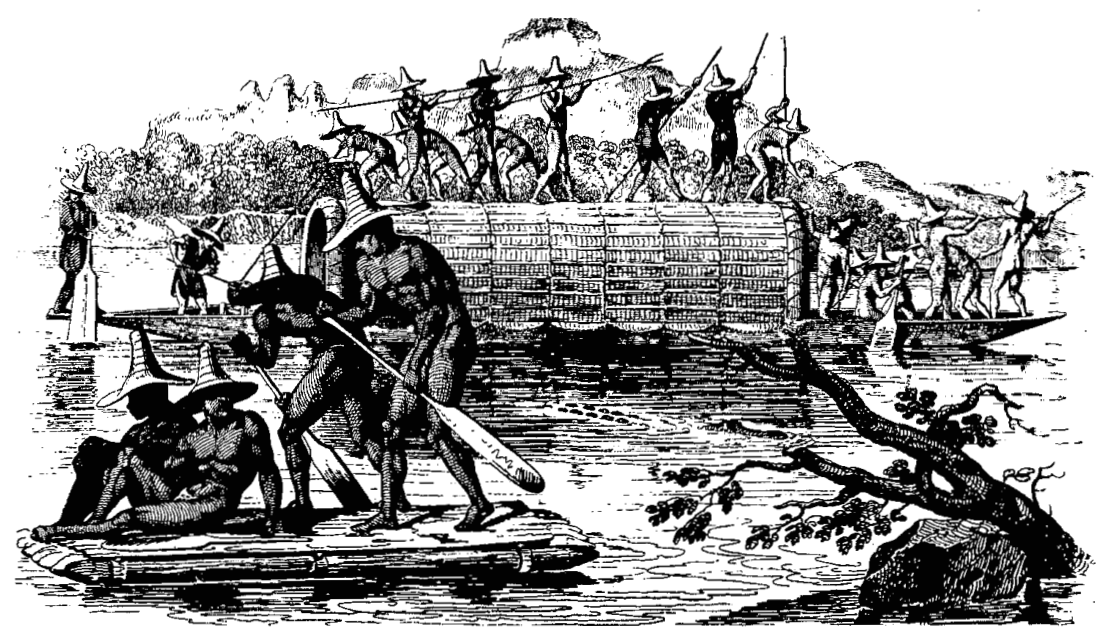

las elecciones a la estabilidad política. Del impulso dado al cambio se podría esperar una democratización, tanto de la vida política como de la vida social y económica del país; de la vida política, porque ampliaría el horizonte de opciones electorales y porque induciría a una modificación en el contenido de la oferta electoral de los partidos políticos; de la vida social y económica, puesto que difundiría -prácticas y actitudes de tolerancia y autonomía como las que al parecer portan los nuevos movimientos sociales. En fin, la democracia emergente no tendría, necesariamente, por qué contraponerse a la democracia tradicional. ${ }^{25}$

Ante estos escenarios, cabemencionar a modo de conclusión un comentario final. El ciclo político que se abre con el pacto de finales de la década de los cincuenta y que aportó procedimientos innovadores e inéditos en el país, ha

\footnotetext{
${ }^{25}$ Esta combinación no implica necesariamente la alineación de estos movimientos sociales a una lógica política y partidarista a la cual se resisten. No
}

llegado a un momento en que es necesario redefinir sus componentes. Esta necesidad de cambio, no obstante, demanda no sólo el mantenimiento sino la revigorización del carácter competitivo de las elecciones. Así, y partiendo de una proposición que da valor positivo a la continuidad del régimen democrático, resulta que la combinación entre la opción de cambio (democracia emergente) y la de continuidad de la tradición democrática es la más atractiva; en caso de concretarse, las elecciones de tipo competitivo continuarán aportando una base institucional para la estabilidad y expansión dela democracia. Sin unas elecciones con estas características, no parece posible esperar esto último.

hay razones para descartar su posible expansión bajo un patrón de coexistencia con las formas tradicionales del quehacer político, entre las cuales el sistema electoral podria convertirse en un mecanismo promotor del cambio. Lo que importa evaluar sería el lugar estratégico que cada uno fuese adquiriendo. Véase Gómez Calcaño, "Los movimientos...", pp. 357-360. 